\title{
Prognosis in Hypertrophic Cardiomyopathy Observed in a Large Clinic Population
}

\author{
Marcel J. Kofflard, MD, David J. Waldstein, MD, Jeroen Vos, MD, and Folkert J. ten Cate, MD
}

\begin{abstract}
Overall annual cardiac mortality in hypertrophic cardiomyopathy (HC) has been reported to be between 2 and $4 \%$, although these numbers are primarily from retrospective studies of patients referred to large research institutions. A clinic population of $\mathbf{1 1 3}$ patients with HC was prospectively studied to assess cardiac mortality in the overall group and in selected subgroups commonly thought to be at high risk for sudden death. The mean age at diagnosis was $37 \pm 16$ years. During follow-up, there were 11 cardiac and 2 noncardiac deaths. The annual cardiac mortality was $1 \%$ (95\% confidence interval 0.2-1.8\%). Because of the small number of deaths, relative risk for cardiac death was not significantly different in the presence of young age ( $\leq 30$ years), family history of HC and sudden death, history of syncope or previous cardiac arrest, or both, ventricular tachycardia on 24hour Holter monitoring, or septal myotomy/ myectomy for refractory symptoms and outflow tract obstruction. It is concluded that HC has a relatively benign prognosis ( $1 \%$ annual cardiac mortality) that is 2 to 4 times less than that prevlously reported.
\end{abstract}

(Am J Cardiol 1993;72:939-943)

From the Department of Cardiology, Thoraxcenter, Academic Hospital "Dijkzigt," Erasmus University, Rotterdam, the Netherlands. Manuscript received December 18, 1992; revised manuscript received and accepted June 3, 1993.

Address for reprints: Folkert J. ten Cate, MD, Academische Ziekenhuis Dijkzigt, Thoraxcenter Ba 350, Dr. Molewaterplein 40, 3015 GD Rotterdam, the Netherlands.
$\mathrm{H}$ ypertrophic cardiomyopathy $(\mathrm{HC})$ is notorious for an increased risk of untimely death, ${ }^{1-3}$ but its actual prognosis is poorly defined. Previous studies reported overall annual mortality rates between 2 and 4\%.-10 These rates for the most part are based on hospitalized patients referred to large research institutions and probably tell a bleaker story than actually exists for the general population of patients with $\mathrm{HC}$, as suggested by a recent study by Spirito et al. ${ }^{11}$ These investigators followed a small number of outpatients with $\mathrm{HC}$ and found no case of sudden death or clinical deterioration over 3 to 6 years.

Recent progress in electrophysiology ${ }^{12,13}$ and genetics $^{14,15}$ has enabled investigators to identify selected patients with particularly high risk for sudden death. Before such highly technical and invasive tests are used in all patients with $\mathrm{HC}$, a more accurate asscssment of the overall prognosis in this disease is needed. Since 1970, we have followed a large number of patients at our $\mathrm{HC}$ clinic, representing the complete spectrum of the disease in regard to clinical presentations and treatment modalities. In our experience with these patients, we have found a remarkably low incidence of cardiac death.

\section{METHODS}

Patient selection: Patients in the $\mathrm{HC}$ clinic at the Thoraxcenter of Academic Hospital "Dijkzigt" generally are in 1 of the following 4 groups: (1) those diagnosed in our hospital or outpatient clinics, (2) those transferred from outlying hospitals for advanced care, (3) outpatients referred from the community for advice and follow-up, and (4) self-referred family members of patients.

Patients with identifiable causes of left ventricular hypertrophy, such as valvular aortic stenosis and uncontrolled systemic hypertension, are not followed in the $\mathrm{HC}$ clinic and are not included in this study.

Between 1970 and 1990, 113 patients were examined initially and at yearly intervals. Before 1979, the diagnosis of $\mathrm{HC}$ was based on clinical parameters alone; after 1979, it was based on the echocardiographic finding of a nondilated, hypertrophied left ventricle (any wall thickness $>15 \mathrm{~mm}$ ) in the absence of known causes of left ventricular hypertrophy. ${ }^{16}$ For children, ventricular hypertrophy was diagnosed in relation to published standards for height and weight. ${ }^{17}$

At the time of the initial visit, clinical characteristics including age at diagnosis of $\mathrm{HC}$, family history of $\mathrm{HC}$ or sudden death in a first-degree relative, or both, history of syncope or sudden death, symptoms and New York Heart Association functional class were recorded. Physical examination and baseline laboratory studies were performed, including M-mode and 2 dimensional echo- 


\begin{tabular}{|c|c|c|}
\hline & & Number $(\%)$ \\
\hline Patients & & 113 \\
\hline Male/female & & $60 / 53$ \\
\hline \multicolumn{3}{|l|}{ Mean age (years) } \\
\hline First visit & & $38 \pm 15$ (range $12-76)$ \\
\hline Diagnosis & & $37 \pm 16$ (range $5-71$ ) \\
\hline \multicolumn{3}{|l|}{ Family history } \\
\hline \multirow[t]{3}{*}{$\mathrm{HC}$} & + & $54(48 \%)$ \\
\hline & 0 & $35(31 \%)$ \\
\hline & - & $24(21 \%)$ \\
\hline \multirow[t]{3}{*}{$H C$ and SD } & + & $40(35 \%)$ \\
\hline & $\circ$ & $52(46 \%)$ \\
\hline & - & $21(19 \%)$ \\
\hline \multicolumn{3}{|l|}{ History } \\
\hline Syncope & & $24(21 \%)$ \\
\hline Cardiac arrest & & $1(1 \%)$ \\
\hline \multicolumn{3}{|l|}{ Symptoms } \\
\hline Dyspnea & & $49(43 \%)$ \\
\hline Angina & & $37(33 \%)$ \\
\hline Palpitations & & $34(30 \%)$ \\
\hline \multicolumn{3}{|l|}{ NYHA functional class } \\
\hline I & & $57(50 \%)$ \\
\hline 11 & & $40(36 \%)$ \\
\hline III & & $16(14 \%)$ \\
\hline IV & & $0(0 \%)$ \\
\hline \multicolumn{3}{|l|}{ Therapy } \\
\hline$\beta$ blockers & & $49(43 \%)$ \\
\hline Calcium antagonists & & $17(15 \%)$ \\
\hline$\beta$ blockers and calcium antagonists & & $6(5 \%)$ \\
\hline Antiarrhythmics & & $4(3 \%)$ \\
\hline \multicolumn{3}{|l|}{$\begin{array}{l}\text { LVOT gradient } \\
\text { (at rest and/or provocation) }\end{array}$} \\
\hline \multirow[t]{3}{*}{$\geq 50 \mathrm{~mm} \mathrm{Hg}$} & + & $38(34 \%)$ \\
\hline & - & $68(60 \%)$ \\
\hline & o & $7(6 \%)$ \\
\hline \multicolumn{3}{|c|}{$\begin{array}{l}\mathrm{HC}=\text { hypertrophic cardiomyopathy; } \mathrm{LVOT}=\text { left ventricular outflow tract; } \mathrm{NYHA}= \\
\mathrm{New} \text { York Heart Association; } \mathrm{SD}=\text { sudden death; }+=\text { present; } 0=\text { absent; }-= \\
\text { unknown or not available. }\end{array}$} \\
\hline
\end{tabular}

cardiography (as well as Doppler echocardiography after 1985), and 24-hour ambulatory electrocardiographic monitoring when possible. Invasive hemodynamic and angiographic studies were performed only in patients with symptoms refractory to medical therapy who were potential surgical candidates. Surgery was recommended if a peak left ventricular outflow tract gradient $>50$ $\mathrm{mm} \mathrm{Hg}$ at rest or with provocation was found.

Follow-up: Patients were assessed on a yearly basis or more frequently, as indicated. All patients were followed exclusively by 1 physician (FJtC).

Follow-up information on patients who moved out of Rotterdam was obtained from their private cardiologists. In cases of death, cause was determined by death certificate or autopsy when available, or by questioning of relatives or physicians involved in the patient's care. Cardiac death was defined as death from myocardial infarction, congestive heart failure or arrhythmia, or sudden death. Sudden death was assumed to be cardiac, and was defined as a witnessed death within 1 hour after the onset of symptoms or an unwitnessed death in a subject known to be alive and functioning normally 24 hours before. ${ }^{18}$ Episodes of successfully resuscitated cardiac arrest during follow-up were classified as cardiac death for the purposes of analysis.
Statistics: Survival estimates and 95\% confidence intervals were calculated according to the Kaplan-Meier method. The yearly mortality rate was calculated on the basis of all available follow-up time. To assess risk factors for cardiac death, univariate analysis was performed using the Cox regression model. For each indicator, the relative risk and $95 \%$ confidence interval are reported.

\section{RESULTS}

Baseline characteristics: Clinical characteristics of the 113 study patients ( 60 male and 53 female) at the time of the initial visit are presented in Table I. The mean age at presentation to our institution was $38 \pm 15$ years (range 12 to 76). Forty-three patients were aged $\leq 30$ years, and 6 patients were $>65$ years at the time of diagnosis. Fifty-four patients reported history of $\mathrm{HC}$ in $>1$ first-degree relative, of whom 40 patients also reported a family history of sudden death at a young age ( $<40$ years). Seven patients reported multiple sudden deaths in the family. No patient had family history of sudden death in the absence of HC. Twenty-four patients had syncope at presentation. One patient had a witnessed cardiac arrest and was successfully resuscitated. Reported symptoms included dyspnea in 49 patients, exertional angina in 37, and palpitations in 34. Fiftyseven patients were asymptomatic or had trivial symptoms (New York Heart Association functional class I), 40 were mildly symptomatic (class II), and 16 were moderately symptomatic (class III). No patient had New York Heart Association class IV.

Baseline medications included $\beta$ blockers in 49 patients, calcium antagonists in 17 , both $\beta$ blockers and calcium antagonists in 6, and antiarrhythmics in 4 .

The diagnosis of $\mathrm{HC}$ was confirmed by 2-dimensional echocardiography in all patients. ${ }^{19}$ Mean left ventricular wall thickness was $22 \pm 4 \mathrm{~mm}$ (range 15 to 40 ). Systolic anterior motion of the mitral valve was present in 64 patients. Left ventricular outflow tract obstruction $>50 \mathrm{~mm} \mathrm{Hg}$ at rest or with provocation was present in 38 patients, as determined by Doppler echocardingraphy or cardiac catheterization, or both. Of 98 patients who had at least one 24-hour Holter monitor, 37 had $\geq 1$ episode of ventricular tachycardia ( $\geq 3$ consecutive ventricular beats) recorded; none of these had sustained (>30 seconds) ventricular tachycardia. Holter recordings were generally obtained without discontinuation of medications.

Follow-up data: No patient was lost to follow-up, and information was obtained in all surviving patients within 6 months of January 1990. Mean follow-up was $7 \pm 6$ years (range 1 to 19 ).

During the follow-up period, 32 patients underwent myotomy/myectomy. One patient underwent concomitant mitral valve replacement for significant mitral valve regurgitation, and 3 underwent concomitant coronary artery bypass grafting for significant coronary artery disease. No patient had intraoperative placement of a permanent pacemaker or automatic implantable cardioverter-defibrillator device; however, 4 patients needed permanent pacemakers after surgery. There was 1 perioperative death, a patient with a preoperative gradient of 
$145 \mathrm{~mm} \mathrm{Hg}$ and class II symptoms, who died of intractable congestive heart failure 21 days after surgery. Three surgical patients died suddenly in late follow-up at a mean of 5 years after surgery.

During the follow-up period, 12 patients died and 1 was successfully resuscitated from cardiac arrest, which in this study is considered a cardiac death. Two patients died of noncardiac causes: 1 at age 53 years from carcinoma of the lung, and 1 at age 76 from a cerebrovascular accident. In the latter patient, a cardiac source of cerebral embolus was considered unlikely. The remaining 11 deaths were cardiac, of which 9 were sudden by defined criteria, including the 3 surgical patients and the 1 cardiac arrest survivor. One patient, the perioperative patient previously described, died from congestive heart failure. The remaining death was in an 80-year-old man who died at home of an undetermined but presumably cardiac cause. One patient who died had proven coronary artery disease.

The mean age at cardiac death was $47 \pm 18$ years (range 26 to 80 ). The annual cardiac mortality in this population was $1 \%$ (95\% confidence interval 0.2 to $1.8 \%$ ). Figure 1 shows the Kaplan-Meier survival curve for patients free from cardiac death.

For the purposes of analysis, patients were divided according to known or suspected risk factors for sudden death, including young age, family history of both $\mathrm{HC}$ and sudden death, history of syncope or sudden death, or both, and presence of ventricular tachycardia on 24hour Holter monitoring. $8,13,20-23$ No statistically significant difference in risk of cardiac death was found in any subgroup (Table II).

\begin{tabular}{|c|c|c|c|c|}
\hline Subgroup & Number & $\begin{array}{l}\text { Cardiac } \\
\text { Deaths }\end{array}$ & $\begin{array}{l}\text { Follow-Up } \\
\text { (years) }\end{array}$ & $R R(C)$ \\
\hline Total & 113 & 11 & $\begin{array}{c}7 \pm 5 \\
\text { (range 1-19) }\end{array}$ & \\
\hline \multicolumn{5}{|l|}{ Age $\leq 30$ years } \\
\hline+ & 43 & 5 & $8 \pm 5$ & $1.36(0.44-4.18)$ \\
\hline 0 & 70 & 6 & $7 \pm 6$ & \\
\hline \multicolumn{5}{|l|}{$\mathrm{FH}$ of $\mathrm{HC}$ and $\mathrm{SD}$} \\
\hline+ & 40 & 3 & $7 \pm 6$ & $0.65(0.17-2.44)$ \\
\hline 0 & 52 & 6 & $7 \pm 5$ & \\
\hline - & 21 & 2 & $9 \pm 5$ & \\
\hline \multicolumn{5}{|c|}{ Syncope and/or cardiac arrest } \\
\hline+ & $31^{*}$ & 4 & $9 \pm 6$ & $1.51(0.48-4.81)$ \\
\hline $\mathrm{O}$ & 82 & 7 & $7 \pm 5$ & \\
\hline \multicolumn{5}{|l|}{ VT on Holter } \\
\hline+ & 37 & 2 & $8 \pm 5$ & $0.55(0.12-2.58)$ \\
\hline O & 61 & 6 & $8 \pm 6$ & \\
\hline- & 15 & 3 & $4 \pm 3$ & \\
\hline \multicolumn{5}{|l|}{ Surgery } \\
\hline+ & 32 & 4 & $8 \pm 6$ & $1.45(0.45-4.61)$ \\
\hline 0 & 81 & 7 & $7 \pm 5$ & \\
\hline $\begin{array}{l}* \text { *includes } 7 \text { patients with } \\
\mathrm{Cl}=95 \% \text { confidence int } \\
\text { absent; } \mathrm{VT}=\text { ventricular ta }\end{array}$ & $\begin{array}{l}\text { follow-up, } \\
\text { ily history; } \\
\text { abbreviatio }\end{array}$ & $\begin{array}{l}\text { relative ri } \\
\text { in Table I. }\end{array}$ & ompared with patie & nhom clinical feature \\
\hline
\end{tabular}

FIGURE 1. Cardiac survival of 113 pa tients with hypertrophic cardiomyopathy. Numbers above horizontal axis refer to numbers of patients at each follow-up period. Vertical hars indicate $95 \%$ conffdence intervals.

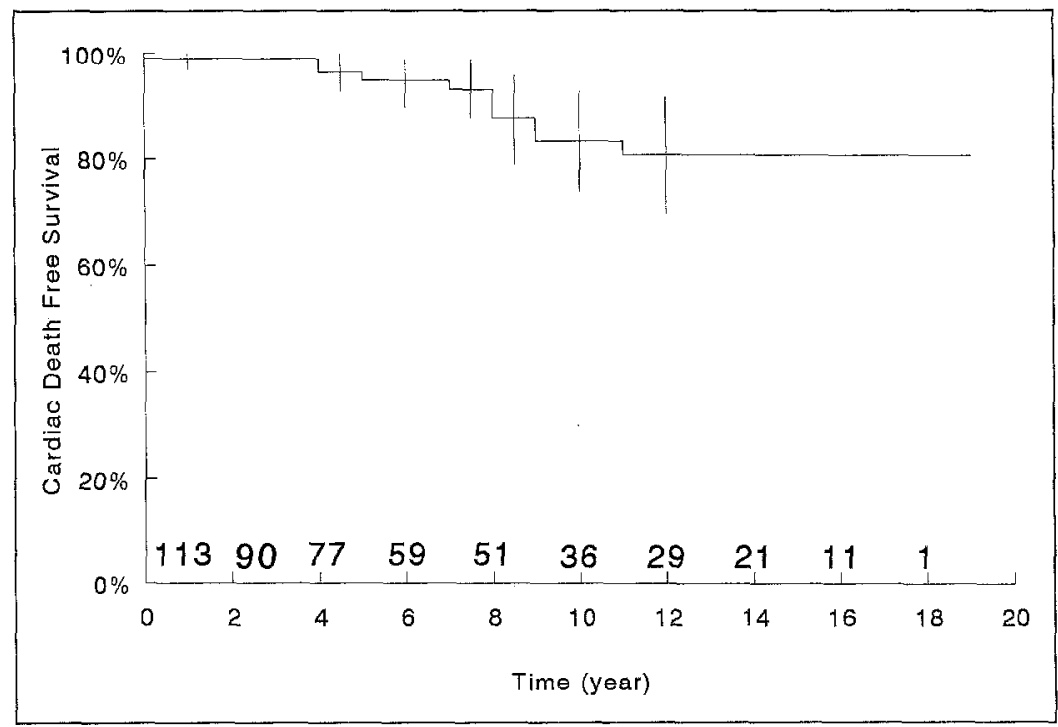




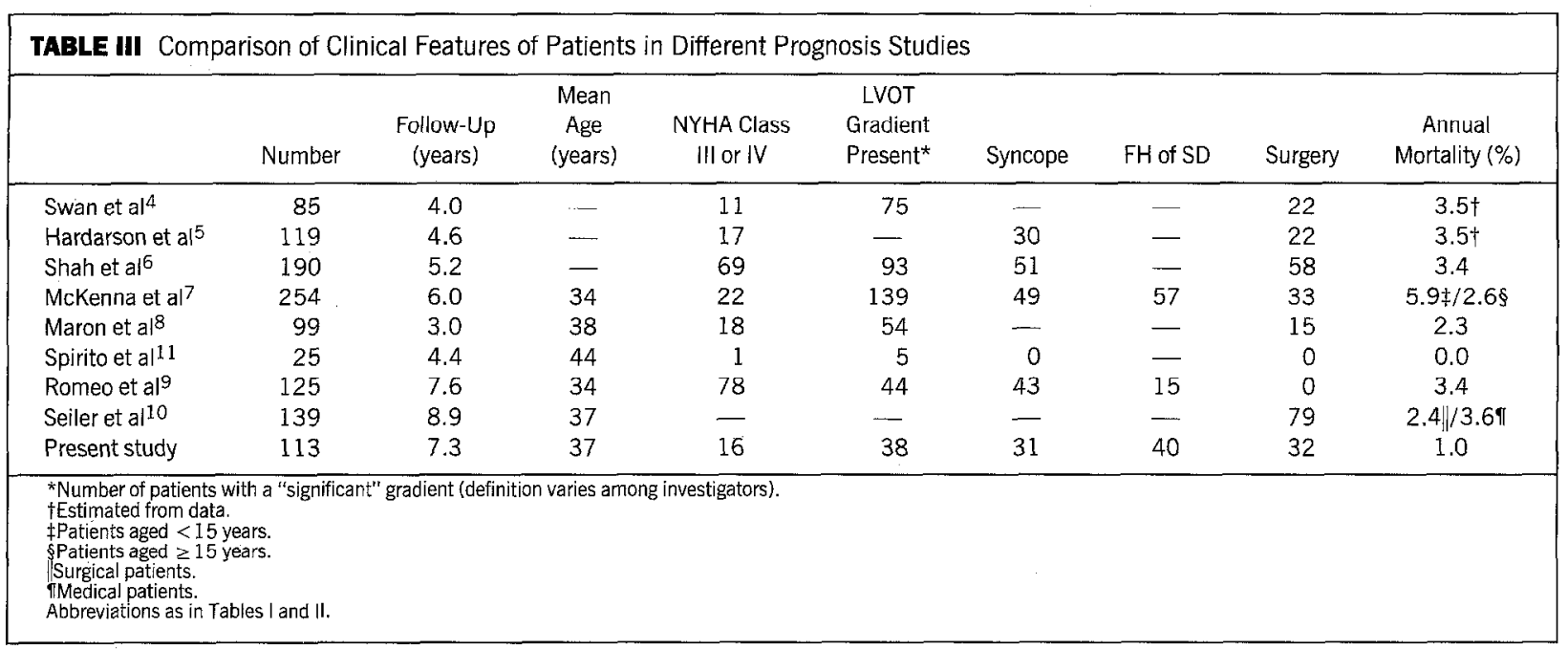

\section{DISCUSSION}

This study is the first to report a benign prognosis for a large, relatively nonselected population of patients with HC. In this population of 113 patients, only 11 died from cardiac causes during an average follow-up of 7 years, yielding an annual cardiac mortality rate of only $1 \%$. Previous prognosis studies reported overall annual cardiac mortality rates of 2 to $4 \%, 4-7,9,10$ with annual mortality rates up to $8.6 \%$ in selected high-risk subgroups (Table III). ${ }^{7,8,13}$ In contrast to those previous studies, the present study is both prospective and allinclusive; the analysis does not exclude patients who are asymptomatic, do not have outflow tract gradients or have had cardiac surgery.

All patients in this study were treated by the same physician according to the following flexible guidelines: initial trial of $\beta$ blockers for relief of symptoms, if present; switch to calcium antagonists if symptoms persist; and surgical therapy for those with medically refractory symptoms in whom a significant outtlow gradient is shown at cardiac catheterization. Antiarrhythmic therapy was used very infrequently. We believe this therapeutic algorithm, although not unique to our institution, may have conferred a survival benefit in these patients.

Of 32 patients who underwent myotomy/myectomy during follow-up, there was only 1 perioperative death. Equally good surgical results were obtained by Seiler et $\mathrm{al}^{10}$ who recently reported only 1 perioperative death in 79 surgical patients. This is in sharp contrast to previous surgical series that reported operative mortality rates as high as $31 \%{ }^{4-7}$ and to current estimated rates of 5 to $8 \% .{ }^{1}$ The present data show a relatively good prognosis for patients surviving surgery, as do previous studies, ${ }^{6,7,10}$ although absolute protection against late sudden death does not occur.

Other investigators have reported favorable prognoses in specific subgroups of patients with $\mathrm{HC}$, including the elderly, ${ }^{24}$ the nonobstructed, ${ }^{25}$ and those with apical hypertrophy. ${ }^{26}$ Only recently was the overall experience in a general HC clinic reported: Spirito et a ${ }^{11}$ found no cases of cardiac death or deterioration in 25 outpatients, although the follow-up period was brief (mean 4.4 years) and the patient cohort small.
As Spirito et al ${ }^{11}$ point out, and we believe correctly, selection bias has likely led to misrepresentation of the true prognosis in $\mathrm{HC}$. They note that most patients in previous studies were hospitalized at 1 of 2 national referral centers. By inference, those patients are sicker and therefore have fatal complications more often than do those such as ours. However, it is difficult to prove the effect of selection bias, because a correlation between presenting clinical features and risk of subsequent death has not been shown in $\mathrm{HC}, 4,6,20,23$ with the possible exception of prior cardiac event ${ }^{7,13}$ and class IV dyspnea. ${ }^{5}$ Although those 2 clinical features are rare in the present study, they are uncommon in other studies as well (Table III).

Because of the low incidence of cardiac death in this population, we were unable to delineate statistically significant risk factors for this outcome. The clinical features commonly believed to confer an increased risk of sudden death include young age, strong family history of sudden death, previous history of syncope or cardiac arrest, and ventricular tachycardia on 24-hour Holter monitor, especially when associated with symptoms. ${ }^{6-8,13,20-23}$ Recent genetic and electrophysiologic studies indentified new risk factors for sudden death, including particular chromosomal abnormalities ${ }^{14,15}$ and the presence of inducible sustained ventricular tachycardia. ${ }^{13}$ However, the present results suggest that applying genetic analysis and electrophysiologic testing to the general population of patients with HC is unjustified. With an annual cardiac mortality of $1 \%$ in $\mathrm{HC}$, such expensive and invasive studies should be reserved only for the few patients known by history to be at exceptionally high risk of sudden death.

These findings also have important implications for the counseling of patients with HC. Although it is still necessary to inform affected patients and their relatives of the potential for sudden untimely death, physicians no longer need to paint an unduly bleak picture. The actual risk of dying in this disease is 2 to 4 times less than that previously reported. With further advances in the detection and treatment of patients at high risk for sudden death, true prognosis in $\mathrm{HC}$ can only be expected to improve. 
Acknowledgment: We would like to thank Ria Eldering for secretarial assistance, and Eric Boersma for help with the statistical analysis.

1. Maron BJ, Bonow RO, Cannon RO, Leon MB, Epstein SE. Hypertrophic cardiomyopathy: interrelations of clinical manifestations, pathophysiology, and therapy. N Engl J Med 1987;316:780-789, 844-852.

2. McKenna WJ, Camm AJ. Sudden death in hypertrophic cardiomyopathy: assessment of patients at high risk. Circulation 1989:80:1489-1492.

3. Maron BJ, Fananapazir L. Sudden cardiac death in hypertrophic cardiomyopathy. Circulation 1992;85(suppl I):I-57-I-63.

4. Swan DA, Bell B, Oakley CM, Goodwin J. Analysis of symptomatic course and prognosis and treatment of hypertrophic obstructive cardiomyopathy, $\mathrm{Br}$ Heart $\mathrm{J}$ 1971;33:671-865.

5. Hardarson T, de la Calzada CS, Curiel R, Goodwin JF. Prognosis and mortality of hypertrophic obstructive cardiomyopathy. Lancet 1973;2:1462 -1467.

6. Shah PM, Adelman AG, Wigle ED, Gobel FL, Burchell HB, Hardarson T, Curiel

$\mathrm{R}$, de la Calzada $\mathrm{C}$, Oakley $\mathrm{CM}$, Goodwin $\mathrm{JF}$. The natural (and unnatural) history of hypertrophic cardiomyopathy: a multicenter study. Circ Res 19/4;34-35(suppl 11): II-179--II-195.

7. McKenna W, Deanfield J, Faruqui A, England D, Oakley C, Goodwin J. Prognosis in hypertrophic cardiomyopathy: role of age and clinical, electrophysiologic and hemodynamic features. Am J Cardiol 1981;47:532-538.

8. Maron BJ, Savage DD, Wolfson JK, Epstein SE. Prognostic significance of 24 hour ambulatory electrocardiographic monitoring in patients with hypertrophic cardiomyopathy: a prospective study. Am J Cardiol 1981;48:252-257.

9. Romeo F, Pellicia F, Cristofani R, Martuscelli E, Reale A. Hypertrophic car diomyopathy: is a left ventricular outflow tract gradient a major prognostic deter minant? Eur Heart $J$ 1990;11:233-240.

10. Seiler C, Hess OM, Schoenbeck M, Turina J, Jenni R, Turina M, Krayenbueh HP. Long-term follow-up of medical versus surgical therapy for hypertrophic cardiomyopathy: a retrospective study. J Am Coll Cardiol 1991;17:634-642.

11. Spirito P, Chiarella F, Carratino L, Berisso MZ, Bellotti P, Vecchio C. Clinical course and prognosis of hypertrophic cardiomyopathy in an outpatient population. N Engl J Med 1989;320:749-755.

12. Fananapazir L, Tracy CM, Leon MB, Winkler JB, Cannon RO, Bonow RO
Maron BJ, Epstein SE. Electrophysiologic abnormalities in patients with hypertrophic cardiomyopathy: a consecutive analysis in 155 patients. Circulation 1989;80: $1259-1268$.

13. Tananapazi- L, Chang AC, Epstein SE, McAreavey D. Plognustic deteminants in hypertrophic cardipomyopathy: prospective evaluation based on clinical, Holter hemodynamic, and electrophysiologic findings. Circulation 1992;86:730-740.

14. Watkins $H$, Rosenzweig $\Lambda$, Hwang DS, Levi $T$, McKenna $W$, Scidman CE, Seidman JG. Characteristics and prognostic implications of myosin missense mutations in familial hypertrophic cardiomyopathy. $N$ Engl J Med 1992:326:1108-1114. 15. Epstein ND, Cohn GM, Cyran F, Fananapazir L. Difference in clinical expression of hypertrophic cardionyopathy associated with two distinct mutations in the beta-myosin heavy chain gene: a $908^{\mathrm{le}} \rightarrow \mathrm{val}$ mutation and a $403^{\mathrm{arg}} \rightarrow \mathrm{glu}$ mutation. $\mathrm{Cir}$ culation 1992;86:345-352.

16. Maron BJ, Epstein SE. Hypertrophic cardiomyopathy: a discussion of nomenclature. Am J Cardiol 1979;43:1242-1244.

17. Feigenbaum $\mathrm{H}$. Echocardiography. Philadelphia: Lea \& Febiger, 1986:621-639. 18. Myerburg RJ, Castellanos A. Cardiac arrest and sudden cardiac death. In: Braunwald E, ed. Heart Disease: A Textbook of Cardiovascular Medicine. Philadelphia: W.B. Saunders, 1988:742-776.

19. Maron BJ, Gottdiener JS, Epstein SE. Patterns and significance of distribution of left ventricular hypertrophy in hypertrophic cardiomyopathy: a wide angle, two dimensional echocardiographic study of 125 patients. Am J Cardiol 1981:48.418 428 20. Frank $S$, Braunwald E. Idiopathic hypertrophic subaortic stenosis: clinical analysis of 126 patients with emphasis on the natural history. Circulation 1968;37: 759-788.

21. Maron BJ, Lipson LC, Roberts WC, Savage DD, Epstein SE. "Malignant" hypertrophic cardiomyopathy: identification of a subgroup of families with unusually frequent premature death. Am J Cardiol 1978:41:1133-1140.

22. MeKenna WJ, England D, Doi YL, Deanfield JE, Oakley C, Goodwin JF. Arthythmia in hypertrophic cardiomyopathy. I: influence on prognosis. Br Heart $J$ 1981:46:168-172.

23. Maron BJ, Roberts WC, Epstein SE. Sudden death in hypertrophic cardio myopathy: a profile of 78 patients. Circulation 1982;65:1388-1394

24. Fay WP, Taliericia RP, Ilstrup DM, Tajik AJ, Gersh BJ. Natural history of hypertrophic cardiomyopathy in the elderly. $J$ Am Coll Cardiol 1990;15:83-90. 25. Aron LA, Hertzeanu HL, Fisman EZ, Nosrati IS, Kellermann JJ. Prognosis of nonobstructive hypertrophic cardiomyopathy. Am J Cardiol 1991;67:215-216.

26. Webb JG, Sasson Z, Rakowski H, Liu P. Wigle ED. Apical hypertrophic cardiomyopathy: clinical follow-up and diagnostic correlates. J Am Coll Cardiol 1990; $15: 83-90$ 